\title{
CONSTITUIÇÃO, DIREITOS HUMANOS E PLURALISMO JURÍDICO: A POSSIBILIDADE DE CONTROLE À JURISDIÇÃO INDÍGENA NO BRASIL A PARTIR DA COMPARAÇÃO COM A CONSTITUIÇÃO EQUATORIANA.
}

\author{
Edna Raquel Rodrigues Santos Hogemann ${ }^{1}$
}

\begin{abstract}
RESUMO: No Brasil, historicamente, temas relacionados à constituição, direitos humanos e pluralismo jurídico estão adstritos à jurisdição do Estado. Tal modelo embora tido como democrático, impõe o direito oficial com sua carga etnocêntrica aos povos indígenas. Assim, o Brasil perde a oportunidade de tornar a jurisdição plural, com reconhecimento pluricultural. Esse ensaio objetiva refletir sobre desafios e possibilidades de controle à jurisdição indígena no Brasil a partir da comparação com a constituição equatoriana, que assimilou o conceito de jurisdição indígena a partir do Novo Constitucionalismo LatinoAmericano. A metodologia da pesquisa é dialética qualitativa, com levantamento bibliográfico e documental de dados.
\end{abstract}

Palavras-chave: Direitos Humanos; Jurisdição indígena; Constitucionalismo latinoamericano; Pluralismo jurídico

\section{CONSTITUTION, HUMAN RIGHTS AND LEGAL PLURALISM: THE POSSIBILITY TO CONTROL THE INDIGENOUS JURISDICTION IN BRAZIL FROM THE COMPARISON WITH THE EQUATORIAL CONSTITUTION.}

\begin{abstract}
In Brazil historically, issues related to the constitution, human rights and legal pluralism are attached to the jurisdiction of the State. Such a model, though regarded as democratic, imposes official law with its ethnocentric burden on indigenous peoples. Thus, Brazil loses the opportunity to make the jurisdiction plural, with multicultural recognition. This essay aims to reflect on the challenges and possibilities of control to the indigenous jurisdiction in Brazil from the comparison with the Ecuadorian constitution, which assimilated the concept of indigenous jurisdiction from the New Latin American Constitutionalism. The methodology of the research is qualitative dialectic, with a bibliographical and documentary survey of data.
\end{abstract}

Keywords: Human rights; Indigenous Jurisdiction; Latin American Constitutionalism;Legal pluralism

\footnotetext{
${ }^{1}$ Pós-Doutora em Direito, pela Universidade Estácio de Sá/RJ, Doutora em Direito pela Universidade Gama Filho - UGF (2006), Mestre em Direito pela Universidade Gama Filho - UGF (2002), Pós-Graduação Lato Sensu em Bioética, pela Red Bioética UNESCO (2010), Pós-Graduação Lato-Sensu em História do Direito Brasileiro, pela Universidade Estácio de Sá - UNESA (2007), Graduada em Jornalismo, pela Universidade Federal do Rio de Janeiro - UFRJ (1977) e Bacharel em Direito pela Universidade do Grande Rio (1999). Professora Adjunta III do Curso de Direito, da Universidade Federal do Estado do Rio de Janeiro- UniRio. Professora Permanente do Programa de Pós Graduação Stricto Sensu, em Direito, da Universidade Estácio de Sá - UNESA/RJ.
} 


\section{INTRODUÇÃO.}

Pesquisa realizada o Instituto Brasileiro de Geografia Estatística apontou que o Brasil possui uma população indígena de 817 mil índios, ou seja, totaliza 0,4\% da população total do país. Existem no país, aproximadamente 225 povos em 456 terras reconhecidas oficialmente e, ainda, 180 línguas e dialetos indígenas, dados que revelam claramente que o país possui uma impressionante diversidade de culturas e etnias (VILLARES, 2013, p.56).

Ao longo da história do país esses povos indígenas foram subestimados etnograficamente pelas invisibilidades a que foram submetidos pelo direito imposto de maneira monista pelo Estado Brasileiro. Paralelamente a essa imposição jurídico-cultural essas nações indígenas, estes tiveram seus recursos naturais, seus locais sagrados, suas terras tradicionais, línguas, saberes locais não somente apropriados, mas principalmente destruídos pelo processo histórico de colonização que se mantém até os dias atuais, que Clastres (2011) denomina como forma de etnocídio.

De algum modo, o resgate dos povos indígenas para o Direito terá como baliza jurídica capital a Constituição Federal de 1988, que à medida em que inaugura uma nova ordem jurídica fundando o Estado Democrático de Direito, atenta para os direitos das minorias e dos vulneráveis.

Conquanto a Constituição Federal de 1988, em capítulo adequado designado "Dos Índios” reconheça direitos fundamentais aos povos indígenas, os quais podem ser citados por exemplar, o direito à organização social própria, costumes e direitos territoriais, seus idiomas próprios, é de demarcar-se que o Estado brasileiro não tem sido consequente no aprofundamento do reconhecimento e da defesa desses mesmos direitos, em especial no que diz respeito à organização social própria, que, ao lado do direito à diversidade, ao pluralismo político e aos valores fundamentes do Estado Democrático de Direito (art.1º da CF/88), são os alicerces normativos possibilitadores a que o Brasil possa adotar uma jurisdição indígena em diálogo com as experiências latino-americanas já em curso, como tratar-se-á no caso da Constituição do Equador.

Assim, o presente promove uma reflexão sobre os desafios e possibilidades de aplicação da jurisdição indígena no Brasil, a partir da comparação com a constituição equatoriana, que assimilou o conceito de jurisdição indígena a partir do Novo Constitucionalismo LatinoAmericano. A metodologia da pesquisa é dialética qualitativa, com 


\section{CONSTITUIÇÃO, DIREITOS HUMANOS E PLURALISMO JURÍDICO: A POSSIBILIDADE}

DE CONTROLE À JURISDIÇÃO INDÍGENA NO BRASIL A PARTIR DA COMPARAÇ̃̃O

COM A CONSTITUIÇÃO EQUATORIANA.

levantamento bibliográfico e documental de dados visando a compreensão e a analise das possibilidades da aplicação da jurisdição indígena, diante do processo de negativa de direitos do sistema de Justiça brasileiro fulcrado no autoritarismo, voluntarismo e decisionismo, que o colocam apartado do diálogo proposto pelo Novo Constitucionalismo Latino-Americano, revelado em constituições como a que se propõe a comparar, como é o caso do Equador.

\section{DO PLURALISMO JURÍDICO À JURISDIÇÃO INDÍGENA RECONHECIDA NA CONSTITUIÇÃO DO EQUADOR.}

Ao considerar que o Direito "é um fato ou fato ou fenômeno social; não existe senão na sociedade e não pode ser concebido fora dela”, Reale (2009, p. 02), que concebe aquela considerada como melhor sistematização da visão culturalista sobre o Direito, sustenta que mesmo as formas mais rudimentares de sociedade constituíam um esboço de ordem jurídica, embora, sem propor seu significado lógico e moral.

A referida tese que pressupõe o direito como fenômeno social é corroborado pelo entendimento de que o Direito é apêndice técnico e, dentro de uma sociedade moral (ou imoral) juntamente com outros elementos culturais, funciona como catalizador da dinâmica social (GEERTZ, 2014, p. 121), isto é, admite o direto como elemento da cultura existente em cada sociedade.

Sucede-se que, a partir da do Séc. XX, em virtude do fenômeno da globalização, se colocou em cada vez maior evidência e conflito a diferença cultural em cenário mundial, com isso, se acendeu o debate acerca do multiculturalismo (MEDEIROS, 2009, p. 588). Fenômeno este, identificado pela coexistência de múltiplas culturas no mesmo espaço social (SACCO, 2013, p. 62).

Esse cenário (multicultural), se conectado à supramencionada tese de que o direito é um elemento cultural, revela a possibilidade da existência de uma multiplicidade de manifestações e práticas normativas concomitantes em um mesmo espaço sociopolítico, fenômeno denominado de Pluralismo Jurídico, frequentemente observado em ordenamentos jurídicos de países formados a partir de uma colônia exploratória, pois, mesmo após a 
independência, restou como legado, um conjunto de regras e institutos arraigados pelo país colonizador (WOLKMER, 2015, p. 257-258).

Além disso, o fenômeno emergente após o Séc. XX, advindo do mal-estar causado pelo Monismo Jurídico ${ }^{2}$ na dinâmica da globalização (SILVEIRA, 2009, p.24-25) ${ }^{3}$ é próprio de classes e grupos sociais oprimidos e se revela como um instrumento eficaz de resolução de conflitos e organização da vida em comunidade, onde o Estado não se faz presente (SANTOS, 2014, p. 334). Ou seja, muito mais que um sistema de resolução de conflitos internos, a juridicidade não oficial aparece como garantia de estabilidade social em sociedades oprimidas.

Reconhecer um cenário de Pluralismo Jurídico não representa renuncia total ao direito estatal, pelo contrário, pode aparecer como meio de integração entre diferentes realidades socioculturais que, mesmo sob a égide do Estado de Direito, possuem mecanismos distintos para a resolução dos conflitos internos (DELLAGNEZZE, 2015).

Destaca-se que o reconhecimento às alternativas de direito, não significa a renuncia ao Direito Estatal, mas, sim, em demonstrar que este é apenas uma das formas jurídicas existentes em uma sociedade; logo, não deve ser interpretado como uma afronta ao Estado e suas instituições (WOLKMER, 2015, P. 268). Por esta razão, “A ausência de um Estado de Direito não implica automaticamente a anarquia social, na medida em que o costume articula e regula as relações sociais” (DAMAZIO, 2008, p. 81).

Assim, estes espaços regulatórios que transitam do local ao nacional e deste ao internacional vão se organizando em diferentes cenários a partir de diferentes concepções funcionais e espaciais onde nenhum deles é dominante e muito menos incompatível com o regime normativo imposto pela ordem jurídica nacional (FARIA, 2017, p. 102).

A partir disso, se Jurisdição significa “manifestação do poder do Estado" (MARINONI; ARENHART; MITIDIERO, 2017, p. 55), a expressão ‘Jurisdição Indígena’ não significa a renuncia ao poder estatal e sim, uma consequência do reconhecimento estatal do

\footnotetext{
${ }^{2}$ Sistema jurídico próprio dos Estados de Direito constituídos a partir da queda do absolutismo, nas palavras de Canotilho (1999, p. 230) têm, como principal fonte de organização jurídica, a Lei proveniente do Estado e guiada pela Constituição Federal, ou seja, “a dimensão de Estado de Direito encontra expressão jurídico constitucional num complexo de princípios e regras dispersos pelo texto constitucional".

${ }^{3}$ Silveira (2009, p. 24-25) sistematiza os principais desacertos do monismo jurídico: a) O monismo foi incapaz de compreender e resolver os diversos problemas de uma sociedade cada vez mais complexo em suas relações intersubjetivas; b) O monismo nos fez caminhar para uma profunda crise no modelo do direito individual, em face das novas e complexas demandas coletivas; c) O monismo concebeu um direito estruturado com a finalidade de colocar e manter no poder uma classe econômica; e d) O monismo não conseguiu superar os problemas reais de eficácia e de validade na distribuição da justiça, tendo privilegiado uma pequena categoria de pessoas em detrimento da grande maioria da coletividade.
} 


\section{CONSTITUIÇÃO, DIREITOS HUMANOS E PLURALISMO JURÍDICO: A POSSIBILIDADE DE CONTROLE À JURISDIÇÃO INDÍGENA NO BRASIL A PARTIR DA COMPARAÇÃO COM A CONSTITUIÇÃO EQUATORIANA.}

fenômeno do pluralismo jurídico decorrente das expressões de direito consuetudinário praticadas nas comunidades indígenas pois, se considerarmos os princípios universais que regem a liberdade individual, implicitamente adotamos o valor de cada povo e a liberdade de agir de acordo com suas próprias leis, o que significa reconhecer "seu direito e sua jurisdição" (SOUZA FILHO, 2006, p. 196).

Nesse contexto, experimentando a aceitação dos termos da Convenção 169 da Organização Internacional do Trabalho (Sobre povos indígenas e tribais) assinada em Genebra, no dia 27 de junho de 1989 e sob a sua influência, ocorreram uma série reformas constitucionais promovidas por países como Colômbia (1991), Peru (1993), Bolívia (1994) ${ }^{4}$, Equador (1998) ${ }^{5}$ e Venezuela (1999) que incluíram em seus Textos Constitucionais alguma forma de reconhecimento ao direito e à jurisdição especial indígena, (FAJARDO, 2003, p. 173).

A citada Convenção, de acordo com o preâmbulo, promove uma revisão nos dispositivos da Convenção 107 (datada de 05 de junho de 1957), também da OIT, ao considerar a evolução do direito internacional desde 1957, bem como as mudanças sobrevindas na situação dos povos indígenas e tribais em diversas regiões do mundo fazem com que seja aconselhável adotar novas normas internacionais nesse assunto, a fim de se eliminar a orientação para a assimilação das normas anteriores;” Além disso, a Convenção tem, dentre outros o objetivo de reconhecer:

as aspirações desses povos a assumir o controle de suas próprias instituições e formas de vida e seu desenvolvimento econômico, e manter e fortalecer suas identidades, línguas e religiões, dentro do âmbito dos Estados onde moram.

Desde esse referencial, Farjado (2004, p. 175) ensina que o reconhecimento da jurisdição indígena nas Constituições dos Estados, busca seu fundamento nos artigos $8^{\circ}$ e $9^{\circ}$ da presente convenção e, se deu a partir de dois conteúdos mínimos: o primeiro parte do reconhecimento do sistema de normas do direito consuetudinário (pluralismo jurídico) e, o segundo, a partir do reconhecimento da jurisdição indígena, ou seja, admite a existência de instituições autônomas, controladas por pessoas legitimadas que em suas atividades poderão a impor decisões que serão eficazes na comunidade e validadas pelo Estado, vide artigos:

Artigo $8^{\circ}$

\footnotetext{
${ }^{4}$ Revogada pela atual Constituição da Bolívia que entrou em vigência em 7 de fevereiro de 2009.

${ }^{5}$ Revogada pela atual Constituição do Equador que entrou em vigência em 20 de outubro de 2008.
} 
1. Ao aplicar a legislação nacional aos povos interessados deverão ser levados na devida consideração seus costumes ou seu direito consuetudinário. 2. Esses povos deverão ter o direito de conservar seus costumes e instituições próprias, desde que eles não sejam incompatíveis com os direitos fundamentais definidos pelo sistema jurídico nacional nem com os direitos humanos internacionalmente reconhecidos. Sempre que for necessário, deverão ser estabelecidos procedimentos para se solucionar os conflitos que possam surgir na aplicação deste principio.

3. A aplicação dos parágrafos 1 e 2 deste Artigo não deverá impedir que os membros desses povos exerçam os direitos reconhecidos para todos os cidadãos do país e assumam as obrigações correspondentes.

Artigo $9^{\circ}$

1. Na medida em que isso for compatível com o sistema jurídico nacional e com os direitos humanos internacionalmente reconhecidos, deverão ser respeitados os métodos aos quais os povos interessados recorrem tradicionalmente para a repressão dos delitos cometidos pelos seus membros. 2. As autoridades e os tribunais solicitados para se pronunciarem sobre questões penais deverão levar em conta os costumes dos povos mencionados a respeito do assunto.

Dentre as Constituições mencionadas, em atenção ao recorte proposto no presente ensaio, dedica-se ao estudo da Constituição Equatoriana de 2008, e em seu texto enfatiza-se e o artigo 171:

Art. 171.- Las autoridades de las comunidades, pueblos y nacionalidades indígenas ejercerán funciones jurisdiccionales, con base en sus tradiciones ancestrales y su derecho propio, dentro de su ámbito territorial, con garantía de participación y decisión de las mujeres. Las autoridades aplicarán normas y procedimientos propios para la solución de sus conflictos internos, y que no sean contrarios a la Constitución y a los derechos humanos reconocidos en instrumentos internacionales.

El Estado garantizará que las decisiones de la jurisdicción indígena sean respetadas por las instituciones y autoridades públicas. Dichas decisiones estarán sujetas al control de constitucionalidad. La ley establecerá los mecanismos de coordinación y cooperación entre la jurisdicción indígena y la jurisdicción ordinaria.

Diante deste dispositivo, é possível identificar os dois conteúdos propostos por Farjado: inicialmente, o reconhecimento do pluralismo jurídico, quando permite o exercício de um “direito próprio” dos povos indígenas; em segundo lugar, o reconhecimento do exercício de uma função jurisdicional alternativa a do Estado, voltada para a solução dos conflitos internos e de limites a sua atuação. (BELLO, 2012, p. 120).

De outro lado, o artigo reprisado expõe dois limites ao exercício deste 'direito próprio’, o primeiro é territorial, verificado a partir da expressão dentro de su ámbito territorial e o segundo material, desvelado a partir do termo que no sean contrarios a la Constitución y a los derechos humanos reconocidos en instrumentos internacionales. No que diz respeito à 


\section{CONSTITUIÇÃO, DIREITOS HUMANOS E PLURALISMO JURÍDICO: A POSSIBILIDADE}

DE CONTROLE À JURISDIÇÃO INDÍGENA NO BRASIL A PARTIR DA COMPARAÇÃO COM A CONSTITUIÇÃO EQUATORIANA.

jurisdição, o Estado Equatoriano envereda às expressões e impõe a elas reconhecimento por parte das autoridades públicas que, contudo, podem estar sujeitas a controle de constitucionalidade. Portanto, apesar de reconhecido, o pluralismo jurídico e a jurisdição indígena, no Estado Equatoriano não possuem plena legitimidade em matéria e alcance territorial.

Outrossim, o referido dispositivo da Constituição Equatoriana, prevê a possibilidade das decisões proferidas pela Jurisdição Indígena suportem averiguação via controle de constitucionalidade, ou seja, enquadrando-se, segundo classificação proposta por Hokema apud Silveira (2012, p. 153), em um pluralismo jurídico formal unitário, o qual, em outras palavras, é reconhecido pelo estado. Contudo, não tem legitimidade plena, sendo passível de controle do direito oficial (estatal), no caso da citada Constituição, o crivo da constitucionalidade.

Destarte, mesmo constitucionalizando o reconhecimento da Jurisdição Indígena e o respeito as instituições e manifestações jurídicas, a Constituição Equatoriana de 2009, impõe limites materiais (nos preceitos constitucionais e direitos humanos reconhecidos em instrumentos internacionais) e territoriais (fronteirando as manifestações a extensão das comunidade indígenas) a essas manifestações, possibilitando, ainda, caso necessário, a possibilidade de verificar as decisões provenientes desta jurisdição em processo de controle de constitucionalidade.

\section{O DIREITO INDÍGENA NA CONSTITUIÇÃO BRASILEIRA DE 1988 E OS LIMITES AO PLURALISMO JURÍDICO.}

Em objetiva análise histórica do direito indígena na cultura do direito constitucional brasileiro, cabe destacar que após o silencio das duas primeiras constituições (1824 e 1891) o Texto promulgado em 1934 foi o primeiro a abordar a questão indígena. A estes, chamados de silvícolas, eram garantidos direitos relacionados à posse de seus territórios (Artigo 129). Sendo certo que as constituições seguintes 1937 (Artigo 154) e 1946 (Artigo 216) conservaram o preceito da Constituição de 1934.

Sob outra perspectiva, a Constituição de 1967, outorgada no contexto do governo militar, expandiu a previsão das constituições anteriores, garantindo aos indígenas, não somente 
a posse das terras, mas também, o usufruto exclusivo dos recursos naturais, em seu (Artigo 186).

Com a promulgação da atual Constituição Federal Brasileira, em 05 de outubro de 1988 o tratamento da questão indígena avança de maneira significativa, pois, além dos direitos reconhecidos nas supramencionadas constituições (posse e usufruto exclusivo da terra), reconhece como direito do índio a preservação da cultura, costumes e tradições, evidenciando, ainda, a terra como elemento de expressão física e cultural das comunidades; atente-se ao artigo 231 caput e $\S 1^{\circ}$ da Carta Magna Nacional, importantes para a compreensão do tema proposto:

Art. 231. São reconhecidos aos índios sua organização social, costumes, línguas, crenças e tradições, e os direitos originários sobre as terras que tradicionalmente ocupam, competindo à União demarcá-las, proteger e fazer respeitar todos os seus bens.

$\S 1^{\circ}$ São terras tradicionalmente ocupadas pelos índios as por eles habitadas em caráter permanente, as utilizadas para suas atividades produtivas, as imprescindíveis à preservação dos recursos ambientais necessários a seu bem-estar e as necessárias a sua reprodução física e cultural, segundo seus usos, costumes e tradições.

Dessa forma, a Constituição de 1988 “foi a primeira a romper com a tradição integracionista do continente” (SOUZA FILHO, 2013, p. 2149), portanto, garante ao indígena o direito de manter a essência de seus elementos civilizatórios.

Em relação às garantias pertinentes as terras, afirma Moron (2013, p. 58) que o conceito de terras para o indígena está ligado diretamente à sobrevivência como povo, em outras palavras, “a terra, para o índio, tem valor superior ao da simples propriedade individual. Ela é a base material da vida indígena” (VILLARES, p. 112), logo, além de espaço geográfico, a terra indígena é local de propagação da cultura e dos métodos de organização social e produção daquele povo.

Ademais, a necessidade da existência física de um território destinado aos povos indígenas como local delimitador da existência de suas crenças, culturas, alimentação, modo de vida, dentre outros fatores que determinam a própria existência de um povo (SOUZA FILHO, 2009, p. 120).

Consequentemente, após um histórico de direitos limitados a demarcação de terras, a Constituição Federal de 1988 mostrou-se um instrumento valioso à proteção dos direitos dos povos indígenas, garantindo a proteção cultural, social e sobretudo, a imprescindibilidade do 


\section{CONSTITUIÇÃO, DIREITOS HUMANOS E PLURALISMO JURÍDICO: A POSSIBILIDADE}

DE CONTROLE À JURISDIÇÃO INDÍGENA NO BRASIL A PARTIR DA COMPARAÇÃO COM A CONSTITUIÇÃO EQUATORIANA.

espaço territorial destes povos como limite geográfico ao exercício dos elementos que identificam aquele povo.

Contudo, mesmo com os avanços trazidos pela Constituição de 1988, “a primeira a romper com a tradição integracionista do continente” (SOUZA FILHO (2013, P.2149) o Brasil, mesmo com todo o “discurso pluralista”, preservando a cultura, costumes e organização social, não abre espaço para expressões jurídicas costumeiras ou culturais, o que prejudica o reconhecimento, pelo aparelho estatal, destas expressões normativas alternativas. (SOUZA FILHO, 2009, p. 117).

Logo, ao contrário das constituições mencionadas no capítulo anterior, o Brasil, não acompanhou as reformas que constitucionalizaram (de forma explicita) as expressões normativas originárias do direito consuetudinário das comunidades indígenas e a jurisdição própria destes povos.

Entretanto, como consequência da incorporação da Convenção 169 da OIT, a partir do Decreto-lei $\mathrm{n}^{\circ}$ 5.051, de 19 de abril de 2004, ingressaram no ordenamento nacional, os artigos que influenciaram o reconhecimento, por parte do estado, deste cenário de pluralismo jurídico (artigos $8^{\circ}$ e $9^{\circ}$, reprisados no item anterior). Dispositivos semelhantes à previsão do artigo 57 do Estatuto do Índio (Lei 6001/73), reconhecendo as manifestações, permite a insurgência do estado, em desfavor de práticas culturais que contraírem os Direitos Fundamentais consagrados pelo ordenamento jurídico estatal e pelos direitos humanos reconhecidos em tratados internacionais.

O destaque da Convenção no Sistema Jurídico Nacional, se dá pelo acolhimento, por parte do Supremo Tribunal Federal (RE 466.343/SP) da tese da supralegalidade e infraconstitucionalidade dos tratados internacionais de direitos humanos. Em outras palavras, os tratados internacionais de direitos humanos, em virtude de sua importância e peculiaridade material, estariam em patamar especial no ordenamento jurídico nacional, abaixo da constituição e acima das leis ordinárias (MAZUOLLI, 2009, p. 120).

Portanto, apesar de não explícitos no ordenamento constitucional, nos termos da Convenção 169 da OIT, são reconhecidos aos povos indígenas a liberdade nas manifestações de direito consuetudinário e, ainda, a manutenção de suas instituições, porém, permite ao estado, a insurreição do Estado em face dos limites materiais impostos, quais sejam: os direitos 
fundamentais reconhecidos pela ordem constitucional e os direitos humanos declarados no âmbito internacional.

Contudo, para respeitar a pluralidade cultural, “a definición e interpretación de los derechos humanos no puede quedar en manos de una sola orientación cultural ni un solo aparato institucional, sin peligro de violentar el derecho a la diversidade” (FAJARDO, 2003, p. 188), isto é, no momento de interpretar os direitos humanos como paradigma limitador das expressões culturais, devem ser levadas em consideração a diversidade cultural, sob pena de afrontar o direito a diversidade cultural.

Tem-se em vista que ao tratar do direito à diversidade cultural, está-se objetivamente discorrendo a respeito do direito à identidade cultural, cuja efetividade depende da execução rigorosa de políticas estatais de reconhecimento, que em vez de concentrar na mera igualdade formal, semelha fundar-se no desejo das comunidades e dos indivíduos de ser diferentes e ser tratados de forma diferente. Não falta quem argumente que o direito a uma identidade cultural parece particularizar e distinguir, e não buscar a igualdade (a que corresponderia, no modo de ver de um sem-número de jusfilósofos, a exemplo de Pérez Luño e Manuel Atienza, o objetivo legítimo dos direitos humanos). Contudo, faz-se oportuno lembrar que a igualdade e a nãodiscriminação entendidas como princípios básicos dos direitos humanos também pressupõem o reconhecimento da etnodiversidade e do direito à diferença (Donders, 2005).

Já na sua formação propriamente moderna o Estado impõe regras - as regras são aquilo que formam esse organismo jurídico-político. E ele procura basear-se nos valores da "maioria”, buscando uma unidade social, um padrão cultural mais homogêneo para a sociedade. O Estado é o centro e tudo deve convergir para este. Formar cidadãos constitui-se em processo conectado às exigências do Estado; conforme argumenta Clastres (2011. p.75), o que se encontra à margem dessa unidade “artificial” é alcançado pelos braços do Estado e deixa de existir como diferença. Partindo dessa premissa, é possível concluir que a sociedade ocidental não é a chave para se entender o etnocídio, mas sim as sociedades com Estado (o exemplo do que se passou em Ruanda está bem ao alcance de nossa memória recente).

Contudo, vale frisar, na esteira da reflexão do autor, que as sociedades como Estado não praticam o etnocídio de forma idêntica (algumas, como a brasileira, se revelam até mais moderadas, vejam o caso da Reserva Raposa Dourada do Sol). É o sistema econômico que interfere na intensidade do etnocídio, e o sistema capitalista com sua busca incansável por 


\section{CONSTITUIÇÃO, DIREITOS HUMANOS E PLURALISMO JURÍDICO: A POSSIBILIDADE}

DE CONTROLE À JURISDIÇÃO INDÍGENA NO BRASIL A PARTIR DA COMPARAÇÃO COM A CONSTITUIÇÃO EQUATORIANA.

produção e crescimento faz, de maneira constante, com que a sociedade ocidental seja especialmente cruel no sentido de aniquilar identidades culturais.

E esse trilhar pautado pelo ódio, competição e pela sombra da exclusão e da morte seletiva e etnocida pode ser superada ou revertida desde que haja vontade política para tal, desde que haja empenho e boa-fé.

Ao escrever a obra, “Sobre a questão judaica”, Marx defende que essa expressão holística do indivíduo é o modo de existência a ser legitimamente conquistada, eliminando as possibilidades reducionistas de explicar a emancipação apenas por meio de vertentes únicas, mas calcadas integralmente em todos os aspectos da sociedade fundante.

Há de se ter em conta que o direito tal como concebido e posto atualidade, ainda segue regido pelo sistema monista e centralizador do modelo de Estado ainda que democrático de direito, mas numa perspectiva de viés político liberal, que objetivamente, em especial no caso brasileiro, não está conseguindo dar uma resposta eficiente em termos de justiça social que contemple simultaneamente as transformações culturais e a necessidade de proteção das tradições e do patrimônio cultural das diversas etnias, especialmente àquelas decorrentes da globalização do capitalismo.

Contraditoriamente, o Estado ao buscar acompanhar a evolução social, e ao lançar mão do princípio da igualdade, sem atentar às especificidades próprias de cada aspecto cultural, acaba advindo em razão dessas mesmas práticas na exclusão social dos grupos que findam por não ter seus direitos protegidos pelo ordenamento jurídico positivo estatal. Tais grupos sociais na medida em que carecem de proteção e garantias, buscam na base dos direitos humanos um aríete de emancipação do Estado; legitimados pelo corpus dos Direitos Humanos, podem reivindicar o ethos de suas próprias regras, muitas delas anteriores ao próprio advento do estado, fruto de usos, costumes e tradições milenares, num universo paralelo ao direito estatal conseguem formar um direito não-estatal, mas reconhecido desde já como direito, embora não oriundo do Estado; muito embora reconheçam a autoridade estatal positivada. Essas práticas pluralistas e sua eficiência na realidade dos Estados, bem como efetividade de suas medidas perante as diferentes barreiras impostas pelo Estado para que a sociedade não realize sua emancipação, evitando também que o direito seja emancipado, foram parâmetro para a densa pesquisa de Sousa Santos. 


\section{CONSIDERAÇÕES FINAIS}

O Brasil constitui-se inequivocamente como uma sociedade pluriétnica e pluricultural, razão pela qual a temática da defesa ao direito à diversidade tem sido tema frequente nas discussões que envolvem o reconhecimento jurídico dos povos indígenas. Entretanto, cumpre apontar nessas considerações finais do presente ensaio, que o Estado brasileiro com suas práticas conservadoras que se revelam como perpetuadoras de uma estrutura de Estado moderno centralizador do direito, objetivamente não reconhece nem sequer implementa ou possibilita a implementação de outras formas de organização cultural em toda a sua amplitude (seja como fato, valor ou norma); mesmo tendo o país realizado a ratificação da Convenção n. ${ }^{\circ} 169$ da OIT; o panorama das relações semi-feudais nesses aspectos do Direito brasileiro se mantém, ainda que diante de um cenário de mundo pós-moderno.

A constatação disso está patente no fato de o Estado e o Direito brasileiros não promoverem um diálogo intercultural com os povos indígenas por meio da implementação da possibilidade da jurisdição indígena a ser realizada pelas próprias autoridades indígenas, nos termos das diretrizes apontadas no bojo da Convenção n. ${ }^{0} 169$ da OIT e implementadas, ainda que nem sempre de forma simétrica com a jurisdição estatal nos países latino-americanos como o Equador.

Essa ausência de diálogo intercultural tem como consequência direta a produção de invisibilidades das formas próprias de resolução de conflitos dos povos indígenas, impondo o monopólio da jurisdição estatal positivada, na figura do Estado. De sorte que o Direito estatal cumpre seu mister de dizer o que é de direito, desde a ótica do explorador, colonizador, mas não necessariamente realiza a justiça.

Razão pela qual, ao cidadão múltiplo indígena não lhe restam reconhecidos preciosos direitos fundamentais, nem sequer a habilitação para o exercício de outros tantos, tais como: direitos consuetudinários, auto-organização, autogoverno, dentre outros.

Há longo caminho a percorrer-se para garantir e adotar-se uma jurisdição indígena e especial, tendo em conta seu estágio de reconhecimento jurídico multicultural e as decisões judiciais no Brasil. De todo modo, um bom início é olhar com apuro a experiência já em curso em outros países do Cone-Sul, como é o caso do Equador. A possibilidade de controle à jurisdição indígena no Brasil a partir da comparação com a constituição equatoriana já é um começo. 


\section{REFERÊNCIAS}

BELLO, Enzo. A Cidadania no Constitucionalismo Latino-Americano. Caxias do Sul: EDUCS, 2012

BRASIL. Constituição. Brasília: Senado Federal, 1988.

Lei 6.001, de 19 de dezembro de 1973. Dispõe sobre o Estatuto do Índio. Diário Oficial da União, Brasília, DF, 21 de dezembro de 1973. Disponível em: <http://www.planalto.gov.br/ccivil_03/Leis/L6001.htm> Acesso em: 01 de abr. 2018.

. Decreto-lei $n^{\circ}$ 5.051, de 19 de abril de 2004. Promulga a Convenção $n^{\circ} 169$ da Organização Internacional do Trabalho - OIT sobre Povos Indígenas e Tribais. Diário Oficial da União, Brasília, DF 19 de abr. de 2004. Disponível em: <http://www.planalto.gov.br/ccivil_03/_ato2004-2006/2004/decreto/d5051.htm> Acesso em: 01 de abr. 2018.

CLASTRES, Pierre. “Do etnocídio”. In: Arqueologia da violência: pesquisas de antropologia política. Tradução de Paulo Neves. São Paulo: Cosac Naify, 2011

CURI, Melissa Volpato. O direito consuetudinário dos povos indígenas e o pluralismo jurídico. Espaço Ameríndio, Porto Alegre, v. 6, n. 2, p. 230-247, jul./dez. 2012. Disponível em: < http://seer.ufrgs.br/EspacoAmerindio/article/view/32216>. Acesso em: 01 de abr. 2018.

DAMÁZIO, Eloise da Silveira Petter. Multiculturalismo versus interculturalismo: por uma proposta intercultural do Direito. Desenvolvimento em Questão, vol. 6, núm. 12, juliodiciembre, 2008, pp. 63-86 Universidade Regional do Noroeste do Estado do Rio Grande do Sul, Ijuí, Brasil. 
DELLAGNEZZE, René. O pluralismo jurídico. In: Âmbito Jurídico, Rio Grande, XVIII, n. 138, jul 2015.2 Disponível em: <http://ambitojuridico.com.br/site/?n_link=revista_artigos_leitura\&artigo_id=16159>. Acesso em: 01 de abr. 2018.

DONDERS, Yvonne. "Para um direito à identidade cultural na legislação internacional dos direitos humanos”. In: de (Org.). Diversidade cultural e o desenvolvimento urbano. São Paulo: Iluminuras, 2005. p.123-142.

FARIA, José Eduardo. O Estado e o Direito depois da crise. $2^{\text {a }}$ Ed. São Paulo: Saraiva, 2017.

FAJARDO, RAQUEL YRIGOYEN. Pluralismo jurídico, derecho indígena y jurisdicción especial en los países andinos. 2003. Disponível em: http://www.cejamericas.org/Documentos/DocumentosIDRC/128elotrdr030-06.pdf Acesso em: 01 de abr. 2018.

GEERTZ, Clifford. O saber local: novos ensaios em antropologia interpretativa. Trad. Vera Joscelyne. 14. ed., Petrópolis: Vozes, 2014.

KELSEN, Hans. Teoria Pura do Direito. trad; João Baptista Machado. $8^{a}$ ed. São Paulo: Martins Fontes, 2009.

MAZZUOLI, Valério de Oliveira. Teoria geral do controle de convencionalidade no direito brasileiro. Revista de informação legislativa, v. 46, n. 181, p. 113-133, jan./mar. 2009 | Revista dos tribunais, São Paulo, v. 98, n. 889, p. 105-147, nov. 2009 | Revista de direito do Estado : RDE, n. 14, abr./jun. 2009.

MEDEIROS, Ana Letícia Baraúna Duarte. Verbete: Multiculturalismo. In Barreto, Vicente de Paula (coord) Dicionário de Filosofia do Direito. São Leopoldo - RS: Unissinos, 2009 p. 588592. 
MORAES, Alexandre de. Direito Constitucional. 29a ed. São Paulo: Atlas, 2013.

MORÓN, Eduardo Daniel Lazarte. As implicações jurídicas e socioambientais na criação de um município em terra indígena, Curitiba: Edição do Autor, 2013.

REALE, Miguel. Lições preliminares de direito. 27. ed. São Paulo: Saraiva, 2009.

SACCO, Rodolfo. Antropologia jurídica: contribuição para uma macro-história do direito. Trad. Carlos Alberto Dastoli. São Paulo: WMF Martins Fontes, 2013.

SILVEIRA, Edson Damas da. Socioambientalismo Amazônico. - $1^{\mathrm{a}}$ ed., (ano 2008), $2^{\mathrm{a}}$ reimpr. Curitiba: Juruá, 2012.

Meio ambiente, terras indígenas e defesa nacional: Direitos fundamentais em tensão nas fronteiras da Amazônia brasileira. 2009. 279 f. Tese (Doutorado em Direito) - Programa de Pós-Graduação em Direito Econômico e Socioambiental, Pontifícia Universidade Católica do Paraná, Curitiba- PR.

SILVA, José Afonso da. Direito Constitucional Positivo. 38 ed. São Paulo: Malheiros, 2015.

SOUZA FILHO, Carlos Frederico Marés de. Comentário aos artigos 231 e 232. In: CANOTILHO, J.J. Gomes; MENDES, Gilmar F.; SARLET, Ingo W.; STRECK, Lenio L. (Coodrs). Comentários a constituição do brasil. São Paulo: Saraiva/Almedina, 2013. p.2148 - 2156.

. O Renascer dos Povos Indígenas Para o Direito. - $1^{\mathrm{a}}$ ed., (ano 1998), $6^{\mathrm{a}}$ reimpr. Curitiba: Juruá, 2009.

STRECK, Lênio Luiz. Jurisdição Constitucional e Decisão Jurídica. $4^{\mathrm{a}}$ ed. São Paulo: RT, 2014. 
VILLARES, Luiz Fernando. Direito e povos indígenas, (ano 2009), 2ª reimpr. Curitiba: Juruá, 2013.

WOLKMER, Antônio Carlos. Pluralismo Jurídico: fundamentos de uma nova cultura no direito. 4. ed. rev. atual. São Paulo: Saraiva, 2015. 